liver weighed $\mathrm{I} 747 \mathrm{~g}$., the stomach $350 \mathrm{~g}$., the stomach contents $200 \mathrm{~g}$. The samples were analyzed according to the Chittenden and Donaldson's modification of Gautier's method.

From a study of the above data it will be seen that the distribution of arsenic is more nearly equal in cases of long duration than those which are more rapidly fatal. More arsenic was found, per $100 \mathrm{~g}$. of tissue, in the cord than in the liver. In a number of cases of acute arsenical poisoning that I have examined, only a trace of arsenic was found in the cord. In the case reported by Scolosuboff, ${ }^{1}$ the brain contained $8.85 \mathrm{mg}$. of arsenic, and the cord $9.33 \mathrm{mg}$. per $100 \mathrm{~g}$. of tissue. Garnier ${ }^{2}$ reports that the brain contained more arsenic than the liver, in two cases of patients who died of tuberculosis, while under treatment with Fowler's solution. In a third case similarly treated the chemical findings were the reverse.

Clinically, the case of E. L. B., here reported, is a typical arsenical poisoning. The symptoms may be classified under four groups:

(I) A period of digestive disturbances, vomiting, diarrhoea followed by constipation.

(2) A hoarse, husky voice as if suffering from a cold.

(3) Headache, numbness in the legs, feet and arm, great tenderness on pressure of the muscles of the legs and arms.

(4) The last period of increased muscular feebleness, complete paralysis, and death.

Chresgo, ILL.

[CONTRIBUTION FROM THE ROCKEFEIILER INSTITUTE FOR MEDICAL, RESEARCH.]

\title{
THE CHEMICAL INDIVIDUALITY OF TISSUE ELEMENTS AND ITS BIOLOGICAL SIGNIFICANCE. ${ }^{3}$
}

By P. A. LRVENE.

Received February 1, 1917.

The principal address of this morning is to deal with the discoveries made in one of those chapters of chemistry, which is fascinating in itself and fascinating because it touches on life, on vital forces, on vitalism, if you choose to so designate them. Evidently the riddle of life still engages the attention of scientists other than biologists; and I presume that it is expected of me to lay before you the contributions made by biological chemistry towards the solution of this problem.

${ }^{1}$ Scolosuboff, Bull. soc. chim., [2] 24, I24 (1875).

Fed a dog $5^{-15} \mathrm{mg}$. of sodium arsenite daily for 34 days.

Found in $100 \mathrm{~g}$. of muscle.......... $0.25 \mathrm{mg}$. of arsenic

Found in roo g. of liver........... $2.71 \mathrm{mg}$. of arsenic

Found in $100 \mathrm{~g}$. of brain.......... $8.85 \mathrm{mg}$. of arsenic

Found in roo g. of cord.......... $9.33 \mathrm{mg}$. of arsenic

2 Garnier, "These," Nancy, I88o, No. 107, p. 47.

${ }^{3}$ An address presented at the meeting of the Chemical Section of the A. A. A. S. in New York, December, r916. 
It is singular that from its early beginnings up to its present maturity biological chemistry busied itself but little with the transcendental. It realized that life is a complex function of an infinite number of variables. It realized that the phenomenon of life could not be revealed before every single individual manifestation of life was interpreted on the basis of chemical structure and of chemical dynamics.

Recent years have established definitely many such relationships, and I shall quote two. I select those which seem to me will stand the test of time and of human scepticism. I select them also because they bring to your attention two methods of investigation employed in bio-chemistry.

I. Living organisms or cells maintain their existence owing to the capacity of their outer membranes for absorption from the outside world and for elimination from within. By the first process the cell obtains materials required for the synthesis of its structural and dynamic elements, by the second it relieves its fluids from unnecessary and cumbersome waste products.

Prof. Jacques Loeb has been engaged for many years in the studies of the factors concerned in the phenomenon of permeability of cell membranes. The conclusion reached on the basis of very ingenious and careful investigation was that the permeability of a living membrane is a function of its chemical structure. ${ }^{1}$ Following the quantitative relationship between permeability and the concentration of potassium salts in the surrounding medium, Dr. Loeb discovered a definite law which connected the two phenomena. The graphic and mathematical expression of the law strongly resembled the one discovered by Hardy for the action of electrolytes on a class of proteins known as globulins. The conclusion is self evident.

2. The second characteristic of living cells or organisms to be referred to here is that of growth. It is a fundamental peculiarity of the living organism, to synthesize its own structural elements from foreign materials. The capacity for synthesis is developed to a different degree in different biological forms. Plants and some bacteria are capable of synthesizing their body protein from carbon dioxide and ammonia. The higher animal organisms require as starting material for the synthesis of their proteins at least amino-acids. Only a few years ago, prior to the work of Fischer, no distinction was made between the food value of individual proteins or individual amino-acids. Recent work of Hopkins, ${ }^{2}$ Röhmann, ${ }^{3}$ and particularly of Osborne and Mendel, ${ }^{4}$ and also of E. V. McCollum $^{5}$ have established most striking relationships between the growth of an animal organism and the structure of the amino-acids available as foodstuff. Thus in a way growth is shown to be a function of chemical structure.

After these preliminary remarks I wish to engage your attention in a third characteristic of living organisms and of living cells and tissues, namely, in their specificity or their individuality. Heredity, evolution, and all that is specifically biological about the living as contrasted with the non-living is pivoting on specificity.

Can this characteristic of living organisms be shown to be a function of chemical structure? Is there among the many components of living tissue one or a group of several that may be regarded as carriers of the specificity of a tissue, of an organ, of a species or of a genus? How can 
this topic be solved? Unfortunately the method has to be indirect for at present it still remains impossible to alter the specificity experimentally. A masterful analysis of the phenomenon is given in the recent book on "The Organism as a Whole" by Jacques Loeb. The conclusions reached there are based on methods of biological research. Can the same problem be approached by chemical methods and if so, how do the conclusions reached by the two methods compare? The view arrived at by Dr. Loeb is formulated by him in the following manner: "Specificity is determined by specific proteins, while some Mendelian characters at least seem to be determined by hormones or by enzymes which need not be specific for the species or genus."

How can this theory be tested by the method of chemistry? The method of reasoning first applied by Hopkins for the analysis of the biological value of different proteins may also fit the present problem. Hopkins compared the data on the composition of gelatin, zein and other proteins and found while the usual proteins contained all the amino-acids present in the molecules of gelatin or of zein, they also contained some amino-acids absent in gelatin or in zein. It was also noted that the gelatin and zein had a different biological value from that of the complete proteins. It was perfectly logical to conclude that the difference in the chemical composition was responsible for the difference in biological action. Hopkins accepted the conclusion and proved it by experiment. Osborne and Mendel and McCollum have placed the conclusion on a very firm basis.

One then is permitted to compare the chemical structure of the principal tissue components, and sieve out those that have a chemical individuality for an individual cell, tissue, organ, species or genus. The elements common in structure to many species and organs cannot be recognized as carriers of specificity. On the other hand, elements constantly varying with the variation of organs, species or genus may be considered an essential factor of the specificities.

Hence a knowledge of the chemical structure of tissue elements is required in order that the riddle of species individuality may be solved by methods of chemistry. Because of this I wish to present briefly the work of recent years on the chemical structure of some of the principal tissue elements.

The principal elements are proteins, carbohydrates, fats, and their complex derivatives, nucleoproteins, glycoproteins, lipoids. There are also enzymes, and, finally, the products of cells activity, hormones and extractives.

For reasons that may seem arbitrary, but are not absolutely so, I shall not adhere to the order of this table, but shall begin the discussion with that of nucleic acids.

As the name indicates these substances are located in the nucleus of the cell; they are constituents which place chromatin and chromosomes in the high esteem of the biologist. The discovery of chromatin by the morphologist was due to that component. Chromosomes are considered by the biologist as carriers of all heredity.

Today we possess enough information on the structure of nucleic acids ${ }^{b}$ to be able to compare the acids of different origin and thus to state definitely whether or not they have an individual structure in different tissues, cells or organs of the plant and animal kingdom, and from this 
to argue whether or not they may be regarded as carriers of any type of individuality of cell or tissue or species, etc.

The appended table shows the structure of nucleic acids as far as they can be visualized at this moment. The structure is rather simple, though at first sight it may seem involved.

Guanylic Acid.

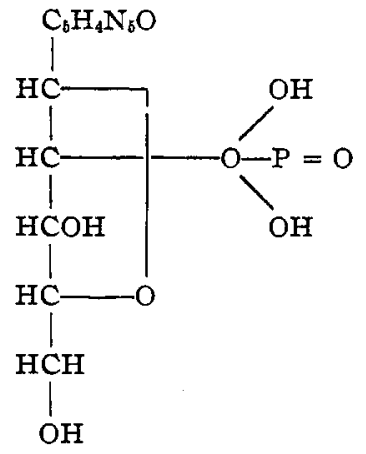

YeAST NUCLEIC ACID.

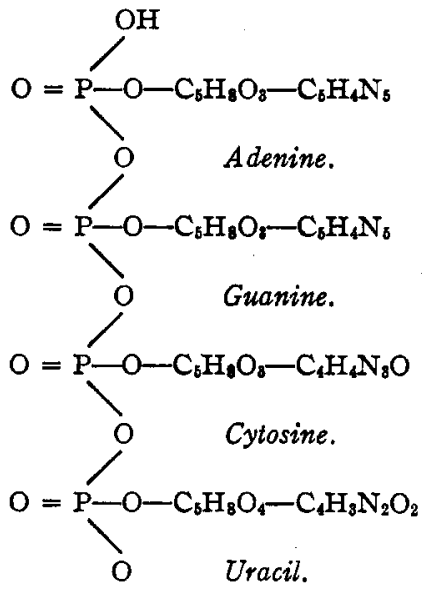

Thymus Nucleic Acid.

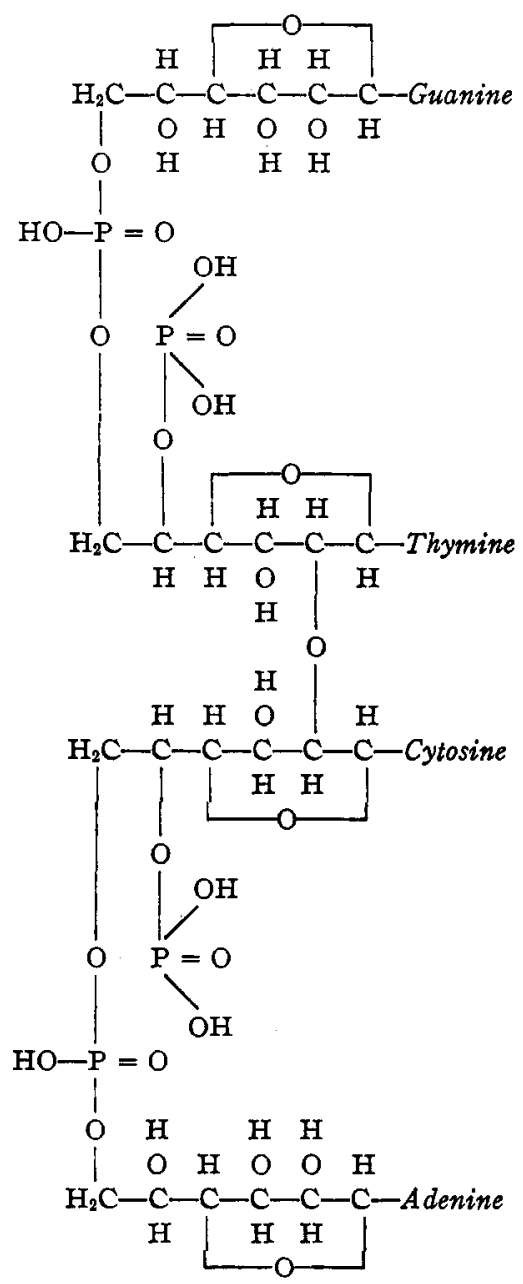

VICINE.<smiles>CN1C(=O)C(NCO)C2NC1=NC2=O</smiles> 
Several nucleotides each composed of phosphoric acid, sugar, and base combine to form the complex nucleic acid. At present a difference is found only for the nucleic acid of the plant and of the animal kingdom. No differences are known for nucleic acids of individual tissues.

Lipoids.-Also to lipoids a great deal of specificity was ascribed by the biologist, even though not so much by the student of heredity as by the one on immunity and similar problems. Also in this instance the chemist could not argue against the biologist. The appended classification and nomenclature demonstrate the many variations in this group of substances accepted by the chemist.7 Unfortunately lipoids suffer from a less accommodating disposition than other tissue components. While nucleic acids offered resistance only on first acquaintance and soon fell in line to form nicely crystalline compounds to the delight of the chemist, lipoids persist in adhering to their disagreeable physical property.

\section{Classification of Lipoids.}

Nitrogen and Phosphorus-free: Cholesterol.

Phosphorus-free: Cerebrosides-Phrenosin (cerebron), kerasin.

Nitrogen and Phosphorus-containing: Monoaminomonophosphatides--I,ecithins, cephalins, paramyelins, myelins, vesalthin, jecorin, monophosphatide from heart muscle; Monoaminodiphosphatides-Cuorin, monoaminodiphosphatide from egg yolk; Diaminomonophosphatides-Amidomyelin, amidocephalin, sphingomyelin, apomyelin, compound from muscle, egg yolk, nerve; Diaminodiphosphatides-Assurin: Triaminomonophosphatides-Neottin, carnaubon, protagon; Triaminodiphosphatides-From nerve, Sahidin.

Sulphur: Cerebrosulfatide.

However, our knowledge of their structure is improving 8 and I venture to predict that within a short time the list of the enumerated substances may shrink considerably. For the present we are certain of the existence of cholesterol, of two galactosides, phrenosin and kerasin, and of the three following phosphatides: lecithin, cephalin and sphingomyelin.

As seen from their graphic formulas their structure is not as complex as originally assumed. Of course it must be added that the formulas here given are only tentative since the question of their structure is not yet a closed chapter for the chemist. However, it is significant that for the present, in our laboratory at least, we have failed to discover any distinction between lipoids derived from different tissues, or different species.

$\begin{array}{ll}\text { Choline } & \mathrm{C}_{5} \mathrm{H}_{15} \mathrm{O}_{2} \mathrm{~N} \\ \text { Stearic acid } & \mathrm{C}_{18} \mathrm{H}_{38} \mathrm{O}_{2} \\ \text { Linolenic acid } & \mathrm{C}_{18} \mathrm{H}_{82} \mathrm{O}_{2} \\ \text { Phosphoric acid } & \mathrm{H}_{3} \mathrm{PO}_{4} \\ \text { Glycerol } & \mathrm{C}_{3} \mathrm{H}_{8} \mathrm{O}_{3}\end{array}$

LECITHIN.

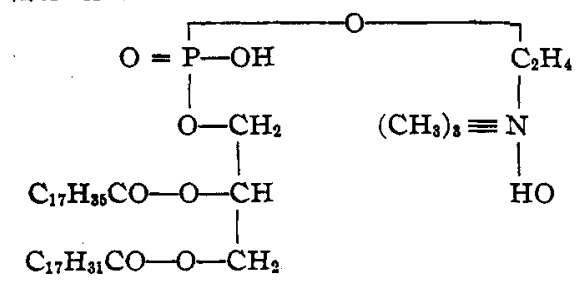

Cerergron.

Cerebronic acid

$\mathrm{C}_{28} \mathrm{H}_{47} \mathrm{CHOHCOOH}$

Sphingosine

Galactose 
<smiles>CCCCCCCC(C=CC(O)C(O)CNC(=O)C(O)CCC)COCC=O</smiles>

Aminoethyl alcohol

Stearic acid

Cephalinic acid

Glycerol

Phosphoric acid

Cephalin.

$$
\begin{aligned}
& \mathrm{C}_{2} \mathrm{H}_{7} \mathrm{ON} \\
& \mathrm{C}_{18} \mathrm{H}_{86} \mathrm{O}_{2} \\
& \mathrm{C}_{18} \mathrm{H}_{32} \mathrm{O}_{2} \\
& \mathrm{C}_{3} \mathrm{H}_{8} \mathrm{O}_{3} \\
& \mathrm{H}_{8} \mathrm{PO}_{4}
\end{aligned}
$$

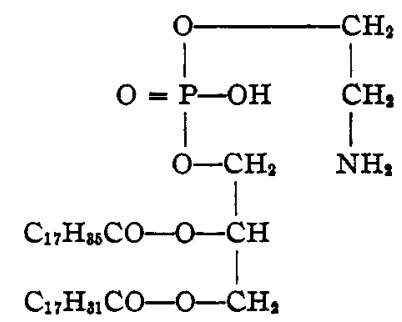

Lignoceric acid

Sphingosine

Choline

Phosphoric acid

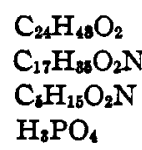

SPHINGOMYELIN.

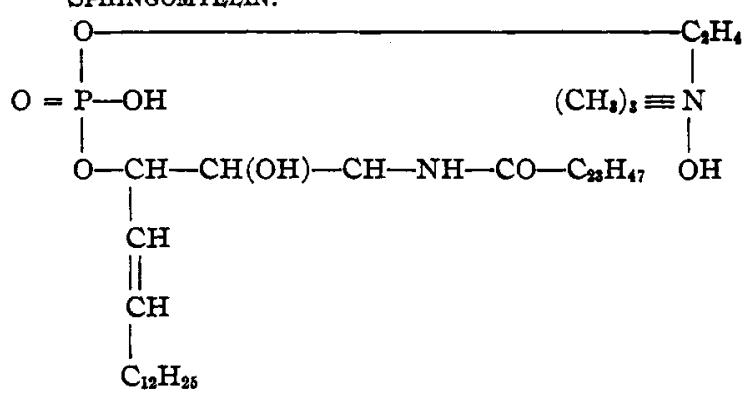

Passing to the third group of substances occurring in all cells and tissues, principally in the outer lining of organs and organisms as mucous membranes, we find that they are all derived from a conjugated sulfuric acid.

The structure of this acid has been explained to a degree, ${ }^{9}$ and is represented on the following chart:

Chondroitrn SUlFuric ACID.

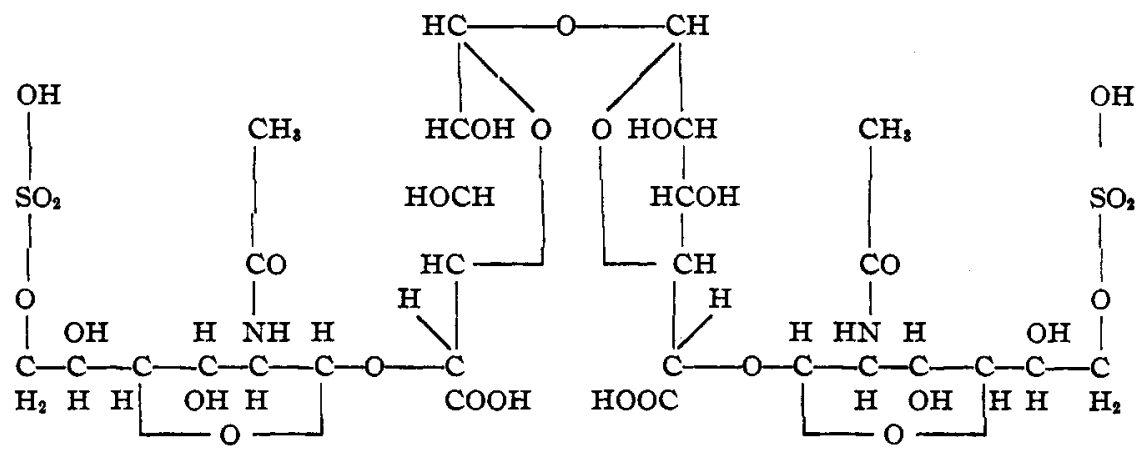


For the present no biological character has been associated with them. The chapter of chemistry dealing with them refers to glucoproteins, mucins, mucoids, paramucoids, and so on. On the other hand, a survey of a number of substances of this group shows that the conjugated sulfuric acid characteristic for them differs only in the configuration of the nitrogenous sugar present in their molecules. Furthermore, apparently there is no connection between this difference and the character of the organ or tissue from which it was extracted.

Glucosamine.

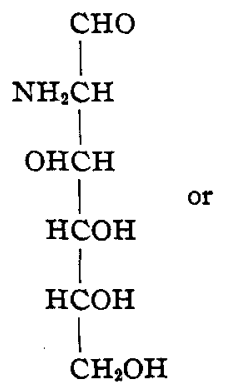

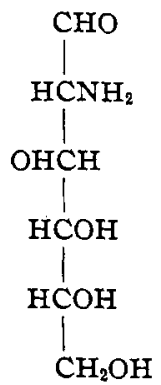

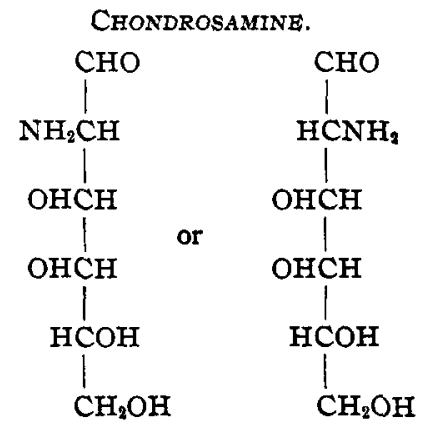

Passing farther to the other tissue components we shall refer only briefly to the mono- and polysaccharides on one and to the fats on the other hand. These substances may differ chemically in different species but they cannot be regarded as carriers of individuality, as it is conceded that their role is principally that of a depot of stored energy.

We shall stop at some length at the proteins. There is scarcely another group of substances as large in membership as this.

Proteins differ from the standpoint of their physical properties and from the standpoint of their component amino-acids. The amino-acids composing an individual protein molecule may differ in proportions and in chemical structure. True, the intimate structure is not known even of the simplest of the proteins. However, there seems to be a well-grounded belief that proteins in the same species differ from tissue to tissue, and that the difference is very decided for proteins of various species. Thus casein of different species is shown to differ in physical properties and in chemical composition; the same is true regarding albumins of different species, also regarding globulins, and particularly so regarding histons and protamins.

Much more striking is the individuality of proteins derived from different species as revealed by the biological test. If an animal receives subcutaneous or intravenous injections of a foreign protein, the serum of the animal, when added to a solution of the protein, forms a precipitate. From this precipitate the original protein may be liberated. The reaction is termed precipitin formation.

If an animal receives an injection of a small quantity of some foreign protein, and after an interval of days receives a second injection of the same protein, it develops a complex of pathological symptoms often leading to death of the animal and known under the name of anaphylaxis.

These two reactions are very specific for proteins of different species, and in a lesser degree specific for individual proteins of the same species. Thus there appears to be both biological and chemical evidence arguing 
for the existence of individual differences between protein of different species, and of different organs and tissues of the same species.

There is also a complete agreement regarding the difference in the enzymes present in different organs of the same animal, and the same organ of animals of different species. This can be best illustrated by reference to the distribution of enzymes engaged in the catabolism of nucleic acids.

The serum of the blood contains an enzyme capable of cleaving the polynucleotide into mononucleotides. ${ }^{10}$ The pancreas gland is capable of splitting a nucleotide into phosphoric acid and nucleoside. The spleen contains also an enzyme capable of hydrolyzing the nucleoside into sugar and base. On the other hand, it was shown by Walter Jones that the organs of different species differ in the character of purine desaminases.

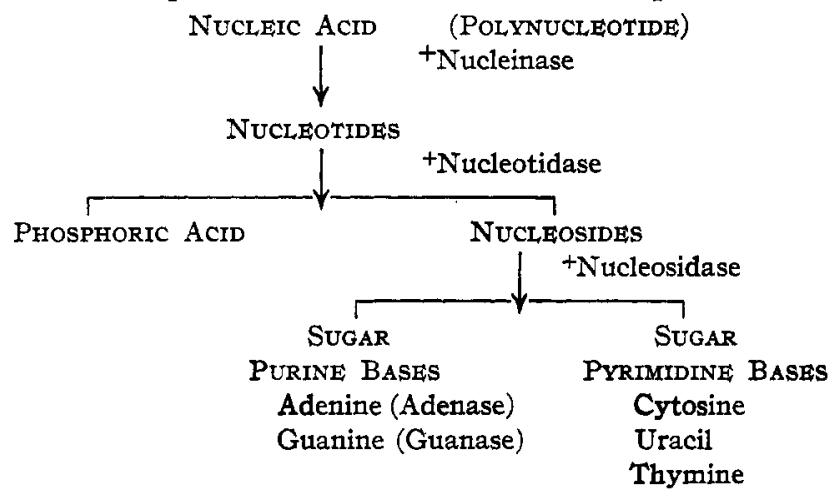

Also in regard to their hormones different organs show a distinct individuality. Hormones are substances produced by the chemical activity of an organ, from where they are thrown into the circulation to stimulate the chemical or physical activity of other organs. Thus the suprarenals, pituitary body, thyroid, pancreas, each gland elaborates a different hormone. But epinephrin of one species need not differ chemically from epinephrin produced by the suprarenal of another species. The same applied to enzymes. Trypsin of one species does not differ from trypsin derived from another species, though by its chemical properties, in the family of enzymes, trypsin is endowed with a strong individuality.

To sum up, there are three groups of substances:

I. Such as nucleic acids, lipoids, conjugated sulfuric acids, which occur in all tissues, all organs of all species, constant, invariable in their structure, present wherever life is present. They are indispensable for life, but carry no individuality, no specificity, and it may be just to accept the conclusion of the biologist that they do not determine species specificity, nor are they carriers of the Mendelian characters.

2. The second group of substances is that of hormones and enzymes. These possess an undisputed chemical individuality. They may be present or absent in one or more organs, in one or another species, but when present in organs of various species may preserve their chemical individuality. In other words, their chemical structure is not a function of species variation. Jacques Loeb attributes to them the role of carriers 
of the Mendelian characters, such as sex, color, and form. This view seems to be quite acceptable from the chemical angle of vision.

3. Finally the third group of substances comprises proteins. These substances seem to show differences of chemical structure with variation of species, and because of this Jacques Loeb ascribes to them the role of carriers of species specificity. It would be comforting to accept this view without doubt or hesitation. But one feels that our knowledge of the structure of proteins is very imperfect. Furthermore, the proteins which show the greatest chemical variation with the variation of species, such as histons and protamins, fail to reveal their individuality by the biological test. Substances, such as primary proteoses, which still contain in their molecule all the amino-acids of their parent substances, all the peculiar grouping of amino-acids of their parent substances, fail to give rise to a positive precipitin test, or to the anaphylaxis test. Thus it would seem that the biological tests perhaps are determined by physical properties and not by chemical structure.

Hence on this point chemistry supports the conclusion of the biologist with some reservation, bearing in mind that when the gaps in the knowledge of the protein structure will be filled the proteins may be relegated to the class of carriers of Mendelian characters.

But then one must admit that the knowledge of the structure of any one tissue element is full of gaps, that all conclusions reached here regarding relation of the chemical structure and biological function are only tentative.

In a way this seems very discouraging. Years of work of chemists of all calibres have failed to complete the knowledge of the structure of even the simplest of the tissue components. And yet there is some encouragement in the thought that long after the mystery of the electron and of the atom will be solved, there will still remain the riddle of life to puzzle the human mind.

\section{References.}

I. Loeb, J., J. Biol. Chem., 27, 339, 353, 363 (1916); 28, I75 (1916).

2. Hopkins, F. G., J. Physiol., 44, 425 (1912); J. Chem. Soc., rog, 629 (r916).

3. Röhmann, F., Biochem. $Z$. (I908-I9I4).

4. Osborne and Mendel, Various papers, J. Biol. Chem. (1912-1916).

5. McCollum and co-workers, Various papers, Ibid., and Am. J. Physiol. (rgr2r9I6).

6. Levene and Jacobs, Ber., 4I, 2073 (1908); 42, 335, I I98, 2 I02, 2469, 2474 , 2703. 3274 (1909); 43, 314I, 3147, 315I (1910); 44, 746, 1027 (I9II); J. Biol. Chem., 12, 377, 41 I, 421 (1912); Levene and LaForge, Ber., 43, 3164 (1910); 45, 608 (1912).

7. Thudichum, J., "Physiological Chemistry of the Brain;" Frankel, S., Biochem. Z. (1908-1910); Rosenheim, O., Biochem. J., 4, 33 I (1909).

8. Renall, M. H., Biochem. Z., 55, 296 (I9I3); Baumann, A., Ibid., 54, 30 (1913); Parnas, J., Ibid., 56, I7 (r913); Levene, J. Biol. Chem., 13, 464 (1912-13); 15, 153, 359 (I9I3); I8, 453 (I9I4); 24, 69 (I9I6); Levene and Jacobs, Ibid., II, 847 (I9I2); I2, 389 (1912); Levene and West, Ibid., 14, 257 (I913); 15, 193 (1913); 16, 419, 549 (I913-14); I8, 477, 48I (I9I4); 24, 41, 63, III (I9I6); 25, 517 (1916).

9. Mörner, Skand. Arch. Physiol., I, 210 (1889); Schmiedeberg, Arch. Exp. Path. Pharm., 28, 358 (1891); López Suárez, Biochem. Z., 56, I67 (I913); Alzona, Ibid., 66, 408 (1914); Levene and La Forge, J. Biol. Chem., 15, 69, 155 (1913); 18, 123, 237 (r914); 
20, 433 (I915); Levene and López Suárez, Ibid., 25, 5 I I (I9I6); 26, 373 (IgI6); Levene and Senior, Ibid., 25, 607 (1916);

1o. Levene and Medigreceanu, J. Biol. Chem., 9, 65, 375, 389 (191 I); Am. J. Physiol., 27, 438 (I9I I). Jones and co-workers, Various papers, 1904-I916; see Jones, "Nucleic Acids."

\section{NEW BOOKS.}

History of the Chemucal Laboratory of the University of Michigan. By EdwaRd D. CAMPBelL, Professor of Chemistry and Director of the Laboratory. 8vo. I66 pages. Published by the University, Ann Arbor.

Instruction in chemistry at the University of Michigan was inaugurated in 1844 upon the appointment of Dr. S. H. Douglas. Laboratory methods were introduced about 1853 being preceded, it would seem, by only Yale (1842) and Harvard (1851). The first building believed at the time to be unsurpassed by anything in the country was one story in height, had three rooms, and cost $\$ 6000$. The six illustrations show in a very graphic manner the method of growth by additions to the original building down to the time of entering the new laboratory in 1909. The main part of the book, I 42 pages, is made up of a roster of all the men who have been on the instructional staff with a list of the scientific papers published by each. These titles from the analytical tables and classic text on qualitative analysis by Douglas and Prescott down to triphenylmethyl by Gomberg, 746 in all, bear an intimate relation to the development of the science of chemistry in this country.

S. W. PARR.

Chemical Discovery and Invention in the Twentieth Century. By Sir William A. TILDEN, Professor Emeritus of Chemistry in the Imperial College of Science and Technology. xvi +487 pp. Illustrated. London: George Rutledge and Sons, Ltd.; New York: E. P. Dutton and Co. Price, $7 / 6$ net.

This extremely interesting book covers four divisions: I. Chemical Laboratories and the Work Done in Them. II. Modern Discoveries and Theories. III. Modern Applications of Chemistry. IV. Modern Progress in Organic Chemistry.

The first part includes a description of the laboratories of the Imperial College of Science and Technology, London, Harvard University, the University of Illinois, the University of Sydney, Australia, and the chemical laboratories of the Federal Polytechnic, Zürich, as illustrations of laboratories for instruction, and descriptions of the laboratories of the British School of Brewing, Birmingham, the Municipal School of Technology, Manchester, the Berlin Technology High School, Charlottenburg, and the Government Laboratory, London, as illustration of laboratories devoted to special purposes.

In the second part the Electric Discharge in Gases, Radium, Genesis and Transmutations of the Elements, Electrolysis, and Architecture of molecules, are among the topics considered. 